Fecha de recepción: febrero 2015 Fecha de aceptación: julio 2015 Versión final: septiembre 2016

\section{La experiencia migratoria como posibilidad de creación}

Alejandro Erbetta *

Resumen: En este ensayo se interrroga sobre cómo la actividad estética, en especial, la fotográfica rinde cuenta de las migraciones y de los procesos de mundialización humana a tavés de los distintos modos que cada autor elige para entablar su discurso visual.

Palabras clave: universalización - singularización - transiciones estéticas.

[Resúmenes en inglés y portugués en la página 75]

(*) Artista. Doctorante contractual de la Universidad Paris 8 Vincennes-Saint-Denis. Director de RETINA.Argentina. Miembro del Laboratorio EA 4010 Arts des Images \& Art Contemporain.

\title{
I
}

Los fenómenos migratorios constituyen una parte esencial de la historia de la humanidad. Son un hecho en la construcción de las sociedades y culturas. Si las migraciones existen desde los orígenes de la humanidad, asistimos actualmente a un fenómeno caracterizado

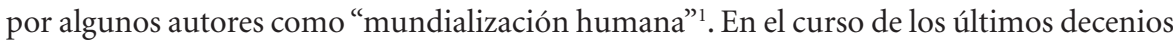
el número de migrantes se ha triplicado, y actualmente casi todas las regiones del planeta estarían implicadas, de una manera u otra, por este fenómeno actual de desplazamiento masivo de las poblaciones humanas. Millones de seres humanos están actualmente en constante movimiento, desplazándose de un territorio a otro por las razones más diversas. La problemática de la migración deviene entonces uno de los grandes desafíos políticos de los Estados-Nación, hecho que presenta, no pocas veces, objetivos contradictorios entre las políticas migratorias de los respectivos países.

Por otra parte las migraciones serían benéficas para las sociedades y las culturas del mundo. El mundo contemporáneo habría entrado en lo que algunos autores denominan como "edad de migraciones", fenómeno producido principalmente por la mundialización económica y liberal que prevalece en las sociedades capitalistas, desde hace algunos decenios. Pero si la mundialización humana es actualmente uno de los desafíos mayores de nuestra sociedad, ¿cómo abordar este fenómeno global a través del arte, particularmente a través de la fotografía? 
El trabajo del fotógrafo brasilero Sebastián Salgado, y su libro Éxodos, servirá como modelo, para analizar esta cuestión de los desplazamientos de poblaciones humanas.

Entre 1993 y 1996, Salgado recorre cuarenta países para realizar un proyecto fotográfico de dimensiones globales. Su propósito es claro: "contar la historia que une humanidad con movimiento" ${ }^{2}$ y demostrar, a través las imágenes, que los acontecimientos planetarios están ligados entre sí. Las problemáticas actuales devienen globales: la diferencia entre los países ricos y pobres, la degradación progresiva del medio ambiente provocada por el hombre, son problemas que afectan a la humanidad entera.

Con un estilo clásico proveniente del fotoreportaje en blanco y negro, Éxodos postula une visión trágica e inquietante de nuestra humanidad. Observando las imágenes del libro, que representan el sufrimiento humano, pero que son al mismo tiempo de una elocuente belleza, se percibe el intento de denunciar uno de los aspectos más sombríos de nuestra humanidad.

El libro, que posee una dimensión épica, está concebido en cuatro capítulos que relatan la odisea de una humanidad en desplazamiento. El primero capítulo, Emigrantes y refugiados, el instinto de sobrevivir, aborda la historia de los migrantes que, plenos de esperanzas, se desplazan dejando sus respectivos países (en general del tercer mundo) para dirigirse hacia los países donde reina la prosperidad económica. Los refugiados, por el contrario, serían aquellas personas, obligadas por las circunstancias, a abandonar sus lugares de residencia para ir a instalarse a otros países, generalmente en condiciones precarias.

Un segundo capítulo La tragedia africana: un continente a la deriva nos muestra la miseria que afecta a la mayor parte de los países de este continente.

Un tercer capítulo América Latina: éxodo rural, desórdenes urbanos detalla el drama de millones de trabajadores rurales que, casi forzados a trasladarse hacia las zonas urbanas, parten en busca de mejores condiciones de vida. La consecuencia de esta movilización masiva ha provocado un impacto considerable en la urbanización de las grandes metrópolis de América Latina (San Pablo, México) que se vuelven incontrolables.

Un cuarto capítulo, Asia: un nuevo rostro humano nos muestra como el éxodo rural hacia las grandes capitales ha creado, en Asia, inmensas megalópolis que se vuelven grandes polos de atracción.

Las imágenes constatan que actualmente la mayor parte de la población humana habita en las zonas urbanizadas, hecho que ha provocado cambios significativos en diferentes niveles: sociales, políticos y culturales. Estaríamos viviendo lo que el antropólogo francés Marc Auge ha denominado como "urbanización del mundo"3.

Éxodos se postula como un documento fotográfico que aborda la historia de la humanidad, y pretende expresar un mensaje: la toma de conciencia.

Las imágenes en blanco y negro, de una estética barroca, poseen un tratamiento de la luz basado en el contraste acentuado de luces y sombras. Los ambientes, con un contenido teatral y cinematográfico, enfatizan un dramatismo de las escenas, que muestran las fotografías de Salgado. Los personajes retratados son elevados, a través de una técnica coreográfica, al rango de personajes casi heroicos, mártires de una humanidad en sufrimiento. Las imágenes, de una gran belleza, poseen connotaciones simbólicas y religiosas, y un cierto misticismo cristiano. Algunos títulos utilizados por el autor (Génesis, Éxodos), hacen referencia a pasajes bíblicos. 
El estilo lírico de Salgado nos muestra, sin embargo, un gran respeto por las personas fotografiadas.

Si Éxodos, representa en imágenes una humanidad a la deriva, un mundo de sufrimientos y contrastes, si intenta darnos un mensaje de alerta, sus imágenes han sido severamente cuestionadas, principalmente en relación a una estetización del sufrimiento.

Parte de la crítica rechaza el contenido estético de fotografías que representan el sufrimiento humano. ¿Como podríamos representar la belleza en el dolor? Para algunos autores esto sería inadmisible. El argumento es que una fotografía del sufrimiento debería poseer principalmente un valor de información.

Esta postura crítica cuestiona duramente una estetización del dolor y pone en dudas que este tipo de fotografías pueda parecerse al arte. Así las fotografías que nos muestran el dolor, perderían una parte considerable de su valor de información por el hecho de ser bellas imágenes. La atención del espectador podría verse desviada de sus propósitos esenciales. Susan Sontag escribe en su artículo La caverna de Platón que una reiteración del acontecimiento puede volverlo menos real y nuestra sensibilidad verse disminuida.

Si las imágenes de Salgado poseen un cierto grado de esplendor, no debería omitirse que uno de los objetivos principales del autor ha sido publicar sus imágenes en la prensa, al menos en un primer momento. Podemos suponer que uno de los fines de la imágenes de Salgado sería el valor de información y la toma de conciencia.

El individuo es el centro de las preocupaciones de la fotografía de Salgado ya que ocupa un espacio central en sus trabajos. Si la crítica puede reprochar una cierta belleza del sufrimiento, su trabajo no podría calificarse de formalista ya que, en sus proyectos artísticos, subyacen contenidos políticos y una emoción del encuentro con el otro. Así, la fotografía de Salgado estaría situada entre la estética y la información, la estética y el compromiso, el documento fotográfico y la obra de arte. Su finalidad primera sería revelar, hacer tomar conciencia, dejar una huella de los acontecimientos, hecho que nos devuelve a la historia. Lo que Salgado registra con sus fotografías, entre 1993 y 1996, es un acontecimiento planetario, histórico, en el que más de 150 millones de personas abandonan sus respectivos lugares de origen para desplazarse y atravesar las fronteras, buscando, no sin sufrimiento, mejores condiciones de vida. Estos movimientos masivos de población han provocado inevitablemente una mutación profunda de nuestro mundo actual.

El carácter global de este proyecto pone en evidencia que se trata de una problemática actual, producida por una mundialización, económica, social, humana y cultural.

Pero si las fotografías de Salgado intentan representar un problema de carácter global para hacernos reaccionar, pueden verdaderamente mostrar la complejidad del problema? ¿Cuando el dolor de los demás es abordado de una manera global, existe un riesgo de desaparición de la singularidad del sujeto?

En su ensayo titulado Ante el dolor de los demás, Susan Sontag, comentando la exposición de Salgado, se pregunta si el principal problema que poseen las fotografías de Salgado no es tanto la belleza que poseen las márgenes del sufrimiento ajeno, sino un reagrupamiento indefinido de esos sufrimientos. Las fotografías de inmigrantes refugiados y exiliados son expuestas sin precisiones ni identificaciones. Los sujetos no son nunca nombrados, tampoco las circunstancias de sus desplazamientos; ello provocaría que el espectador se encuentre desprovisto de elementos para comprender o imaginar una acción posible. 
Sontag hace igualmente alusión a los comentarios de Roland Barthes, a propósito de la exposición organizada por Edward Steichen en 1955, The Family of Man, en la cual dicho autor remarcaba que una tendencia al universalismo podía ser manipuladora. Mostrar una multitud de personas anónimas que sufren, y todas de la misma manera, borraría las causas y motivos particulares de estos sufrimientos individuales. Habría entonces, según el autor, un deslizamiento del sufrimiento hacia la abstracción.

Por nuestra parte pensamos que si las fotografías de Salgado pretenden hacernos comprender una problemática que concierne a la humanidad, el tratamiento de dicho problema de manera global conllevaría el riesgo de dejar al espectador sin referencias.

Mismo si el compromiso de Salgado es remarcable, y existe una inmersión por parte de autor en el sujeto abordado, el sufrimiento que muestran las imágenes, de manera general, podría hacer olvidar, al espectador, el sufrimiento individual de cada persona.

Ahora bien, más que mostrar imágenes del sufrimiento de una manera directa, ¿una evocación poética de dicho problema podría despertar la conciencia del espectador?

Es por esta razón que más adelante abordaremos el problema, a través del caso particular del artista migrante. Nuestro objetivo será intentar mostrar cómo dicho problema puede ser abordado de una manera particular, poniendo en relieve las singularidades de las experiencias vividas.

\section{II}

Pero si la globalización es un fenómeno actual, ¿qué vínculo podría existir entre arte y mundialización? ¿Cómo la mundialización podría afectar la vida de los artistas, las obras de arte? ¿Cómo los artistas, pertenecientes a varias culturas, trabajan este problema?

Los años 1990 marcan el punto de partida de múltiples interrogaciones surgidas de diferentes campos disciplinarios. En el curso de los últimos decenios, los cuestionamientos han estado centrados en la idea de una historia del arte global. Las teorías y pensamientos de descentramiento del arte ubican en el centro de sus análisis las cuestiones relativas a las migraciones y transferts culturales. La conjunción entre arte y mundialización provoca un reajuste de los análisis sobre las prácticas artísticas. Abordando el campo de la estética, Nicolás Bourriaud intenta definir una "estética de la globalización" 4 . Las reflexiones que propone el autor están ancladas en la realidad efectiva de los desplazamientos. Así nos propone una manera de pensar influenciada por un modo de vida nómade, que él mismo practica. Con propiedad, critica la ausencia de relación vital que existe, en general, entre la crítica y las obras. Inspirándose en lecturas de Walter Benjamín y de Georges Bataille, desarrolla un pensamiento por fragmentos, como si el ritmo de su escritura formaría una metáfora de la discontinuidad, de sus idas y vueltas entre diferentes regiones del mundo. El pensamiento posmoderno habría concentrado principalmente sus críticas contra el modernismo, sobre todo en la frontera que separa el mundo entre colonizadores y colonizados, y sus teorías terminarían siendo discursos de deconstrucción sin perspectivas de un diálogo constructivo. Bourriaud propone repensar la noción de modernidad a partir de sus problemáticas específicas, que serían propias de nuestra contemporaneidad. Si el modernismo fue occidental, la época contemporánea atraviesa un problema de globalización 
que concierne a todas las culturas. Algunos artistas, críticos y pensadores habrían avanzado ya en una nueva dirección, que se encuentra esbozada, pero debe todavía definirse. Sería a través de la práctica de ciertos artistas, que podrían definirse nuevos conceptos, como lo que el autor postula como altermodernidad.

\section{III}

En Europa, se asiste actualmente a la emergencia de una generación de artistas originarios de países no reconocidos por el mercado del arte, que, por sus visiones particulares del mundo, son incorporados progresivamente a la escena internacional.

El trabajo del artista de origen albanés, Adrián Paci, representa uno de estos casos.

En 1997 el artista abandona Albania, para refugiarse, junto a su familia, en Italia. Su experiencia del exilio, el choque de la separación y la adaptación a un nuevo país y a una nueva cultura, definen el contexto de sus primeras obras, las cuales intentan reencontrar las raíces de su pasado.

"El hecho de estar en la intersección de dos caminos, en la frontera de dos identidades separadas, se encuentra en todas mi producciones" .

En 2013 el artista presenta en el museo Jeu de Paume, su exposición Vies en transit (Vidas en tránsito), una retrospectiva de su trabajo artístico: un conjunto de instalaciones, pinturas, fotografías y videos que tratan los temas de la migración, la identidad y el exilio.

Las obras de Paci emergen de un encuentro con una experiencia o una historia, y el contexto social en el que vive deviene significativo, ya que representa una fuente de inspiración artística.

Su ambición es crear un vínculo entre pasado y presente, entre el aquí y el allá. Su trabajo se sitúa en un entre-dos, en un momento de transición.

Home to go (2001), es una de las obras representativas de Adrian Paci. El artista concibe dos versiones diferentes de la misma obra. Se trata en principio de una escultura del cuerpo del artista, semidesnudo, cargando sobre sus espaldas, fragmentos de techo de una casa. Luego esa misma obra es presentada como una serie de fotografías en color, que lo muestran, como en la escultura, semidesnudo, transportando, con ayuda de cuerdas, un fragmento de techo de un hogar. Solamente las partes íntimas de su cuerpo son recubiertas con retazos de telas blancas, lo cual nos remite a las vestimentas utilizadas por los romanos en la antigüedad. La serie de fotografías exhibidas en el museo Jeu de Paume, se compone de nueve imágenes de gran formato, de 103 x $103 \mathrm{~cm}$ cada una. Presentadas en una secuencia fotográfica, las imágenes devienen un conjunto homogéneo, donde el espectador percibe las tentativas de desplazamiento del artista, en una acción que él mismo realiza, no sin esfuerzo. En una de las imágenes de la serie, el artista parece mirar directamente al espectador, como interpelándolo. Un sufrimiento se percibe en su mirada. De rodillas, de pie, otras veces casi recostándose en el suelo, las imágenes nos muestran los movimientos forzosos del artista intentando desplazarse.

La obra contiene, al mismo tiempo, una connotación religiosa cristiana, y nos reenvía a las imágenes del camino de Cristo hacia el monte Gólgota, donde tendrá lugar su crucifixión. Aquí el peso que el artista parece soportar, es tal vez, el de su propia historia: su familia, 
su infancia, su pasado, su bienestar, su sufrimiento, que lo acompañan siempre, donde sea que vaya. Es el peso de su propia vida, que debe soportar en sí mismo, como el peso de la propia cruz que soportó Cristo, como el que cada uno debe llevar en el camino de su propia existencia.

Según Edna Moshenson, en su ensayo, "Sujetos en Tranisto" la estructura que soporta el artista en sus espaldas, haría igualmente referencia a la arquitectura típica del pueblo natal de Paci, simbolizando un fragmento de la memoria, una protección. Al mismo tiempo contiene un grado de responsabilidad y compromiso. El hecho de tomar la decisión de partir junto a su familia, y dejar su tierra de origen, es un compromiso motivado por la determinación de aventurarse a ir más lejos, dejando detrás un contexto difícil. En 1997, momento en que Paci decide irse de Albania, reina un clima general de incertidumbre política en el país, producido por una profunda crisis económica y una anarquía generalizada, consecuencia de la salida reciente del régimen comunista del país. El artista decide entonces partir, junto a su mujer y su pequeña hija, para instalarse en Italia y comenzar una nueva vida. La obra Home to go, se presenta entonces como metáfora de su vida y de su propia condición de inmigrante. Representa asimismo, como le dice Edna Moshenson, una figura híbrida: un hombre-casa que se desplaza por el mundo, entre sufrimiento y esperanza, entre movilidad e inmovilidad, entre pausa y movimiento, posibilidad e imposibilidad. La misma hace una referencia explícita de la idea retour chez soi o retorno al hogar, que deviene una idea central para el artista. "Para mí el retorno al hogar no evoca solamente la cuestión de la emigración, sino también una cuestión más profunda, la búsqueda de una estabilidad perdida. En un contexto de mutación profunda debemos elaborar estrategias para sobrevivir. La idea del retorno al hogar o a uno mismo es una de ellas"6. Así la obra de Paci es una metáfora de nuestra época y una expresión de uno de los grandes temas de nuestro mundo contemporáneo, como la inmigración, el desplazamiento y el exilio. A través de sus manifestaciones artísticas, que devienen metáforas visuales, el artista pretende evocar una dimensión colectiva, a partir de una experiencia personal.

\section{IV}

Mi trabajo de creación artística y de investigación teórica es, entre otros, una interrogación sobre mi propia historia y mi propia identidad. Estos problemas, de carácter personal, me habitan desde hace algunos años, y son, actualmente, el centro de mis preocupaciones artísticas y existenciales.

Entre 2009 y 2012, intenté, a través de un trabajo artístico, responder a ciertas cuestiones que me habitaban. Me había vuelto un inmigrante, lo cual me llevaría a reflexionar sobre mi propia situación. Es en esta deslocalización, que se produce un proceso de construcción de una nueva identidad. Este proceso continua siendo una de mis preocupaciones centrales. En este proyecto artístico, titulado Reprises, proponía algunas tentativas para reconstruir la historia de mi familia de origen italiano, que había emigrado a la Argentina. Mis antepasados formaron parte de la gran ola de emigrantes que partieron hacia América Latina a fines del siglo XIX. Un siglo después yo mismo viviría una experiencia similar, aunque por razones diferentes y en otras condiciones. 
En este proyecto las fotografías de álbumes de familia y algunas narraciones orales, se entrecruzan con fotografías realizadas en mis viajes a la región de los orígenes familiares (el norte de Italia), e igualmente con archivos y documentos históricos encontrados en el curso de mis investigaciones. Así, las historias orales, la memoria, y los archivos se vuelven puntos importantes para mi reflexión. Son el vínculo entre el pasado, el presente y el futuro y me han permitido partir de hechos históricos para reinterpretarlos.

El objetivo de este proyecto es reconstruir, en imágenes-textos, la historia de mi familia, de hilvanar parcialmente el vínculo entre generaciones y crear nuevas filiaciones a través de los silencios, el vacío y lo desconocido de la historia familiar. Como en una novela histórica, he partido de la traza de algunos hechos existentes, para construir una narración, y poder así reconstruir una posible historia.

¿Pero cómo reconstruir nuestra propia historia cuando hay silencios, elementos que se nos escapan, o lo desconocido? ¿Cómo remplazar eso que falta o está ausente? ¿Puede reconstruirse una historia de manera fragmentada, dispersa, no lineal? ¿Puede reconstruirse el pasado y la memoria a través de la ficción? ¿Cuál sería su legitimidad?

En este sentido, la apropiación de la historia familiar, así como de la Historia colectiva, es para mí, una posibilidad de reconstitución y recreación de una posible historia, y de reconstruir así mi propia identidad.

De carácter autobiográfico, mi proyecto intenta ir más allá de mi historia personal, y aborda la historia de la emigración europea hacia Argentina hacia fines del siglo XIX. Establecer un dialogo entre historia individual y colectiva, es uno de mis objetivos esenciales. En una época como la nuestra, donde la mundialización humana, económica y cultural deviene uno de los desafíos mayores de nuestra sociedad contemporánea, me pregunto si es posible vivir sin memoria y sin identidad. Siendo un artista migrante, viviendo lejos de mi tierra, el tema del desplazamiento humano es una problemática que me concierne y que deseo profundizar en mis investigaciones. Las nociones de deslocalización, identidad, memoria constituyen puntos importantes de mi reflexión.

Mi trabajo artístico se articula en torno a un dispositivo donde se entremezclan narraciones, documentos históricos, fotografías de viajes, de familia y archivos, elaborando una narración donde temporalidades se entremezclan y dialogan en otra temporalidad, compleja, no lineal. Todas estas tentativas que he realizado como artista para construir un territorio propio, un imaginario, un lugar memorial narrativo, son elementos que me constituyen y me acompañan en mis itinerarios, mis desplazamientos, mis deslocalizaciones.

Mi propia condición de inmigrante ha estado, a pesar de las dificultades, al servicio de una apertura espiritual y hacia los intercambios. La integración a una nueva lengua/cultura me ha dado puntos de vista singulares en relación a mi propia historia y a mi propia cultura. En un proceso de afirmación individual, construí una identidad que no posee una sola raíz, sino es más bien diversa. Una identidad plural se ha ido formando en el seno de estratificaciones de las diversas culturas asimiladas por mi conciencia.

Si el arte es el encuentro entre el artista y la sociedad, una posible respuesta por parte del artista sería una afirmación del yo hacia el resto, el otro.

Pero mi trabajo no es solamente la afirmación del yo. Traducido por el hecho de vivir entre culturas diferentes, el mismo propone una dialéctica entre arte y existencia, que luego se transpone en mi obra artística. 
La migración planetaria se intensifica desde los años 1980, a tal punto que el número de migrantes se ha triplicado y estas cifras no cesan de aumentar. El problema de la migración ocupa entonces un lugar central en las discusiones actuales.

Los artistas no están ausentes de estas discusiones. Frente a la complejidad del mundo, esbozan ideas, proponen proyectos, piensan el futuro, algunos parten a vivir lejos de su tierra. Hemos visto como en Éxodos se documenta la reorganización de la humanidad bajo el efecto de la globalización mundial, que tiene como protagonistas los migrantes, refugiados, exiliados. Como lo muestran las imágenes de Salgado estas problemáticas devienen globales, y afectan a la humanidad entera.

El tratamiento global de este problema podría bascular, como lo pensaba Sontag citando a Barthes, en una posible desaparición de la singularidad de cada individuo, cada historia individual y de su sufrimiento particular.

Hemos intentado entonces mostrar el problema desde una perspectiva diferente, podría decirse opuesta, a través del caso de artistas que trabajan a partir de sus propias historias individuales y familiares, pero que se encuentran siempre íntimamente ligadas a sus contextos históricos.

Así, el caso particular de Adrian Paci, representa la figura de un artista migrante. A través de sus obras el artista albanés elabora estrategias para reencontrar una estabilidad perdida. La experiencia migratoria deviene así un ejemplo concreto de la búsqueda que es el conocimiento de uno mismo. Una práctica artística que traspone cuestiones existenciales a la obra.

Respecto a mi trabajo, uno de mis objetivos ha sido abrir mi problemática, de inspiración personal, hacia problemas más generales como la migración, la memoria individual, familiar y colectiva.

Finalmente los artistas migrantes atraviesan fronteras geográficas, políticas, culturales y se instalan en un nuevo país, una nueva cultura, traduciendo a través de su arte la experiencia de desarraigo, difícil de sobrellevar, pero rica en apertura hacia los otros. Estos artistas forman parten de una nueva cultura transnacional que se desplaza. Algunos denuncian las desigualdades del mundo, como las fotografías de Salgado. Otros, como Paci o yo mismo, encarnan en sus obras la experiencia migratoria haciendo de ella una posibilidad de creación. Pensar los problemas de la migración, el desarraigo, o el exilio, deviene importante, ya que son temas esenciales que conciernen a nuestra época actual. Estos artistas, expresan a través de sus obras, historias individuales y colectivas y proponen nuevas vías de reflexión para repensar estas problemáticas globales.

\section{Notas}

1. Término utilizado por Catherine Wihtol de Wenden (2009) en La globalisation Humaine, Presses Universitaires de France, Paris.

2. Salgado Sebastiao con Francq Isabelle (2013), De ma terre à la terre, Presses de la renaissance, Paris, p. 88. 
3. Augé Marc (2012), Pour une anthropologie de la mobilité, Éditions Payot \& Rivages, Paris, p. 106-107.

4. Bourriaud Nicolas (2009), Radicant. Pour une esthétique de la globalisation, Editions Denoël. (Bourriaud Nicolás (2009), Radicante, Buenos Aires, Adriana Hidalgo).

5. Paci Adrian (2013), Vies en Transit, entrevista con Marta Gili y Marie Fraser. Mousse Publishing, Milan / éditions du Jeu de Paume, Paris / éditions du Musée d'art contemporain de Montréal,Moshenson Edma, Sujets en Transit, p. 44.

6. Ídem.

Abstract: The essay poses the question about how aesthetics in photography give account of migrations and human globalization processes through the different ways that each author chose to build its visual discourse.

Key words: globalization - singularization - aesthetics transitions.

Resumo: Neste ensaio se interroga sobre como a atividade estética, e em especial a fotográfica, mostra as migrações e os processos de mundialização humana através dos diferentes modos que cada autor escolhe para iniciar seu discurso visual.

Palavras chave: universalização - singularização - transições estéticas. 